\title{
UNA PRÁCTICA ENRIQUECIDA DESDE LAS RAÍCES AFROCOLOMBIANASYEMBERAS DE LA PESCA ARTESANAL EN BOCAS DE SATINGA, NARIÑO
}

\section{An Enriched Practice from the Afro-Colombian and Embera Roots of Artisanal Fishing in Bocas de Satinga, Nariño}

\section{Uma prática enriquecida desde as raízes afrocolombianas e emberás da pesca artesanal em Bocas de Satinga, Nariño}

\section{Karen Lorena Angulo Quiñones}

Fecha de recepción: 4 de abril de 2017

Fecha de aceptación: 13 de junio de 2017

Ninguna práctica pedagógica es neutra. Todos están apoyadas en cierto modo de concebir el proceso de aprendizaje y el objeto de ese aprendizaje. Emilia Ferreiro

\section{Resumen}

Este artículo de investigación está enfocado en la práctica integral II, realizada en el municipio Olaya Herrera de la cabecera municipal de Bocas de Satinga, Nariño, en el segundo periodo del año 2015 con los estudiantes del grado cuarto de primaria, en la jornada mañana de la Institución Educativa Comercial Litoral Pacífico (Inelpac). Esta práctica se realizó con el objetivo de identificar la memoria biocultural que tiene origen en la pesca artesanal como estrategia de enseñanza-aprendizaje de la biología en los estudiantes, conociendo su contexto, costumbres, historia; además, sus problemáticas ambientales a partir de sus concepciones y realización de estrategias pedagógicas y didácticas orientadas a motivar y reconocer la diversidad del municipio.

Con el fin de generar espacios de comunicación, reflexiones y discusiones, se desarrolló metodológicamente el modelo holístico trasformador de lan Francesco (2002), por medio del método etnográfico, desde un enfoque de investigación cualitativo, con el que se implementan dos fases: la primera consistió principalmente en una observación participante, y la segunda, se trató de implementar técnicas como entrevistas semiestructuradas, registros fotográficos y audiovisuales en la comunidad educativa y con actores locales del municipio (afrocolombianos y grupos indígenas Embera), lo que permitió recoger evidencias del enriquecimiento cultural en la comunidad. Estas muestras fueron sistematizadas para la obtención de los resultados y su análisis, al integrar experiencias desde el ámbito personal y profesional y consolidar interacciones entre el contexto cultural y biológico, saber local y saber científico, lo que permitió reconocer y valorar el conocimiento tradicional y los recursos biológicos en la relación del ser humano con la naturaleza, la investigación y conservación de la diversidad biológica y cultural de nuestro país.

Palabras clave: Comunidad afrocolombiana y Emberá; concepciones; memoria biocultural; pesca artesanal; practica integral; problemática ambiental. 


\section{Abstract}

This research paper focuses on Comprehensive Practice II, which was carried out at the Olaya Herrera municipality in Bocas de Satinga, Nariño, during the second half of 2015 with second-grade students from the morning session at Institución Educativa Comercial Litoral Pacífico (Inelpac). This practice was carried out with the purpose of identifying the biocultural memory that originated from artisanal fishing as a strategy for teaching-learning biology in students, by getting to know their context, costumes and history, as well as its environment problematics based on its concepts and the fulfilment of pedagogical and didactic strategies aimed at encouraging and recognizing the municipality's diversity.

Aiming to create spaces for communication, reflection and discussion, Ian Francesco's (2002) holistic transformation model was carried out methodologically through the ethnographic method, from a qualitative investigation approach, with which two phases are implemented: the first one consisted mainly of a participating observation, while the second one attempted to implement techniques such as semi-structured interviews, photographic records and audiovisuals in the educational community and with local actors from the municipality (Afro-Colombians and indigenous Embera groups) which allowed the collection of evidences from the community's cultural enrichment. These samples were catalogued to obtain the results and their analysis, by integrating experiences from the personal and professional fields and by consolidating the interactions between the cultural and biological context, from the local and scientific knowledge. This made it possible to recognize and appreciate the traditional knowledge and the biological resources in the relationship between humans and nature, the research and the preservation of both the biological and cultural diversity of our country.

Keywords: Afro-Colombian and Embera community; concepts; biocultural memory; artisanal fishing; comprehensive practice; environmental issues.

\section{Resumo}

Este artigo de pesquisa está focado na prática integral II realizada no município Olaya Herrera da cabeceira municipal de Bocas de Satinga, Nariño no segundo período do ano 2015 com os estudantes de quarto grau do período da manhã da Instituição Educativa Comercial Litoral Pacífico (Inelpac). Esta prática realizou-se com o objetivo de identificar a memória biocultural que tem origem na pesca artesanal como estratégia de ensino-aprendizagem da biologia nos estudantes, conhecendo seu contexto, costumes e história, além de suas problemáticas ambientais a partir das concepções e a realização de estratégias pedagógicas e didáticas orientadas a motivar e reconhecer a diversidade do município.

A fim de gerar espaços de comunicação, reflexões e discussões, o modelo holístico transformador de lan Franceso (2002) se desenvolveu metodologicamente por meio do método etnográfico desde um enfoque de pesquisa qualitativo com o qual duas fases foram implementadas; a primeira consistiu principalmente em uma observação participante e, na segunda, tentou-se implementar técnicas como entrevistas semi estruturadas, registros fotográficos e audiovisuais na comunidade educativa e com atores locais do município (afro colombianos e grupos indígenas emberá); isto permitiu recolher evidências do enriquecimento cultural na comunidade. Estas amostras foram sistematizadas para a obtenção dos resultados e sua análise, ao integrar experiências desde o âmbito pessoal e o profissional e consolidar interações entre o contexto cultural e biológico, o saber local e o saber científico. Isto permitiu reconhecer e valorizar o conhecimento tradicional e os recursos biológicos na relação do ser humano com a natureza, a pesquisa e a conservação da diversidade biológica e cultural de nosso país.

Palavras-chave: Comunidade afro colombianas e Emberá; concepções memoria biocultural; pesca artesanal; prática integral; problemática ambiental 


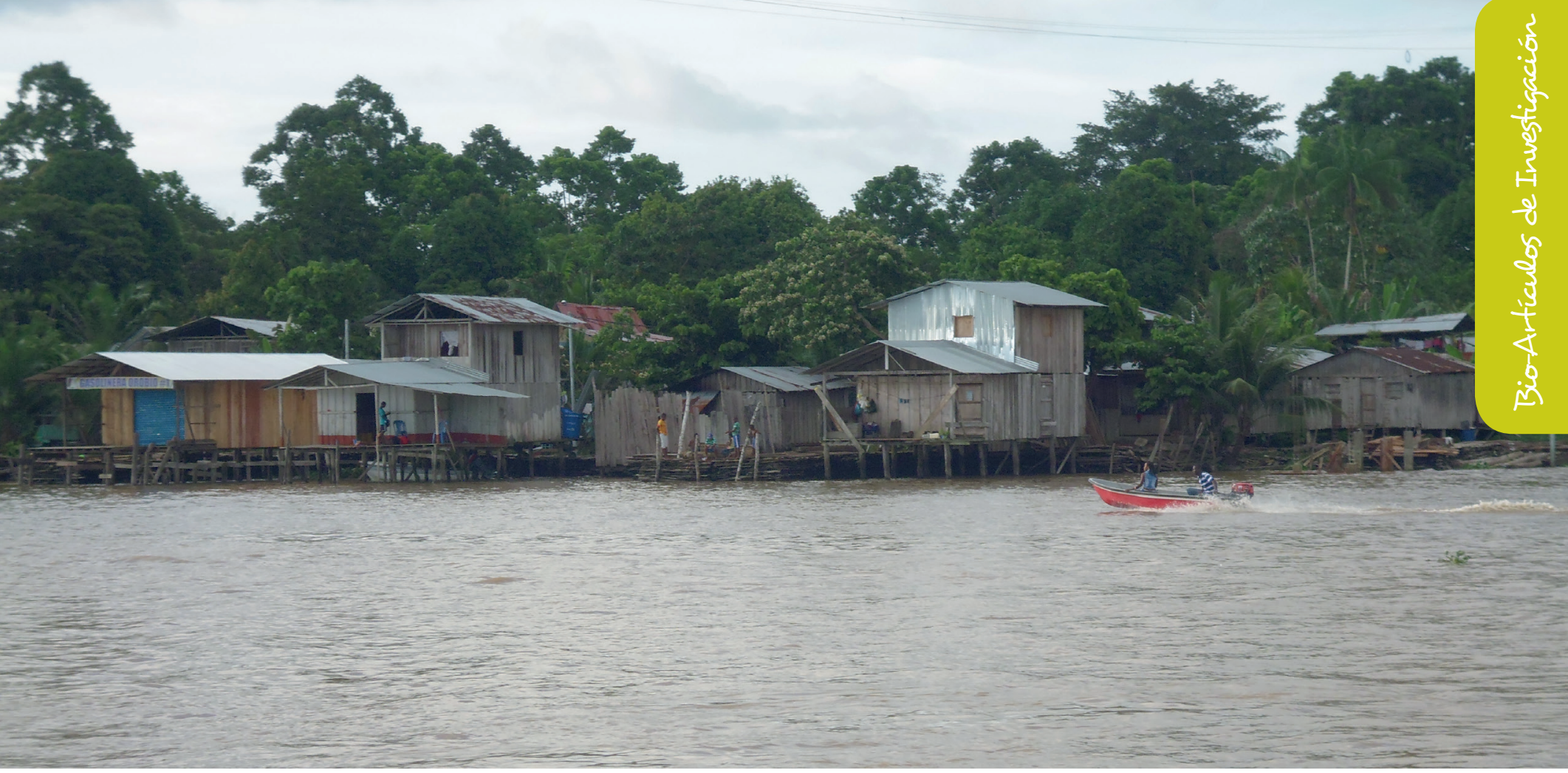

Imagen 1: Bocas de Satinga. Foto tomada por: Angulo, K. (2015)

\section{Introducción}

Las experiencias que se forjan durante la vida se fundamentan en las necesidades que se enfrentan a lo largo del tiempo y de su mismo entorno, de diversas maneras de actuar, de comunicarse y de vivir, característico de un país como Colombia que es una nación rica en culturas, lenguas y paisajes que comprenden las diversas manifestaciones multiétnicas y pluriculturales, biológicas, sociales, y étnicas (Cordoba y Rovira, 2004). Estas surgen de las interrelaciones, saberes y costumbres que se construyen de una tradición histórica a través del tiempo que transcurre de generación en generación.

En ese sentido, surgió la necesidad de realizar un proyecto investigativo que tenga como fin recuperar, reconocer y comprender la biología y la articulación de los saberes tradicionales de una región con el conocimiento biológico que se desarrolla a través de los conocimientos adquiridos por la experiencia, de tal manera que estos puedan integrarse y relacionar aspectos que intervienen directamente en la población. El objetivo general estuvo enfocado en identificar los fundamentos de la memoria biocultural en relación con la pesca artesanal como estrategia en la enseñanza-aprendizaje de la biología en los estudiantes del grado cuarto de primaria de la Institución Educativa Litoral Pacífico (Inelpac). Para esto, se tuvo en cuenta la participación de pescadores, maestros y habitantes de la comunidad como padres de familia (ver imagen 2), por lo que se hizo necesario reconocer en la escuela las diferentes situaciones que modifican en su gran mayoría el diario vivir en Bocas de Satinga.

De esta manera, se pudieron indagar los conocimientos, prácticas y creencias sobre la pesca artesanal en los estudiantes del Inelpac, con el propósito de orientar el desarrollo de las actividades con miras a la apropiación de los saberes y de la diversidad biocultural del contexto regional afrocolombiano, lo que aporta algunas reflexiones pedagógicas desde el proyecto de práctica investigativa. Esto, además, permitió reconocer las habilidades como licenciada en biología que contribuyen a la enseñanza-aprendizaje de la biología a partir de la memoria biocultural asociada a los saberes ancestrales de la comunidad, siendo importante rescatarla para mantener esa historia trazada por nuestros antepasados afrocolombianos y que implica apropiarse de la identidad de quien habita en cada una de sus regiones, como es el pacífico colombiano, considerado como una de las regiones del mundo con una alta diversidad biológica, cultural y social. Este es el contexto del municipio Olaya Herrera que corresponde a la cabecera municipal de Bocas de Satinga y que representa uno de los lugares característicos de la costa Pacífica por acoger a la población afrocolombiana principalmente y en sus veredas cercanas a las comunidades indígenas como los Embera, caracterizados como gente de rio (Ministerio de Cultura República de Colombia, 2010), que se encargan en su labor principal de la pesca artesanal y del cultivo. 


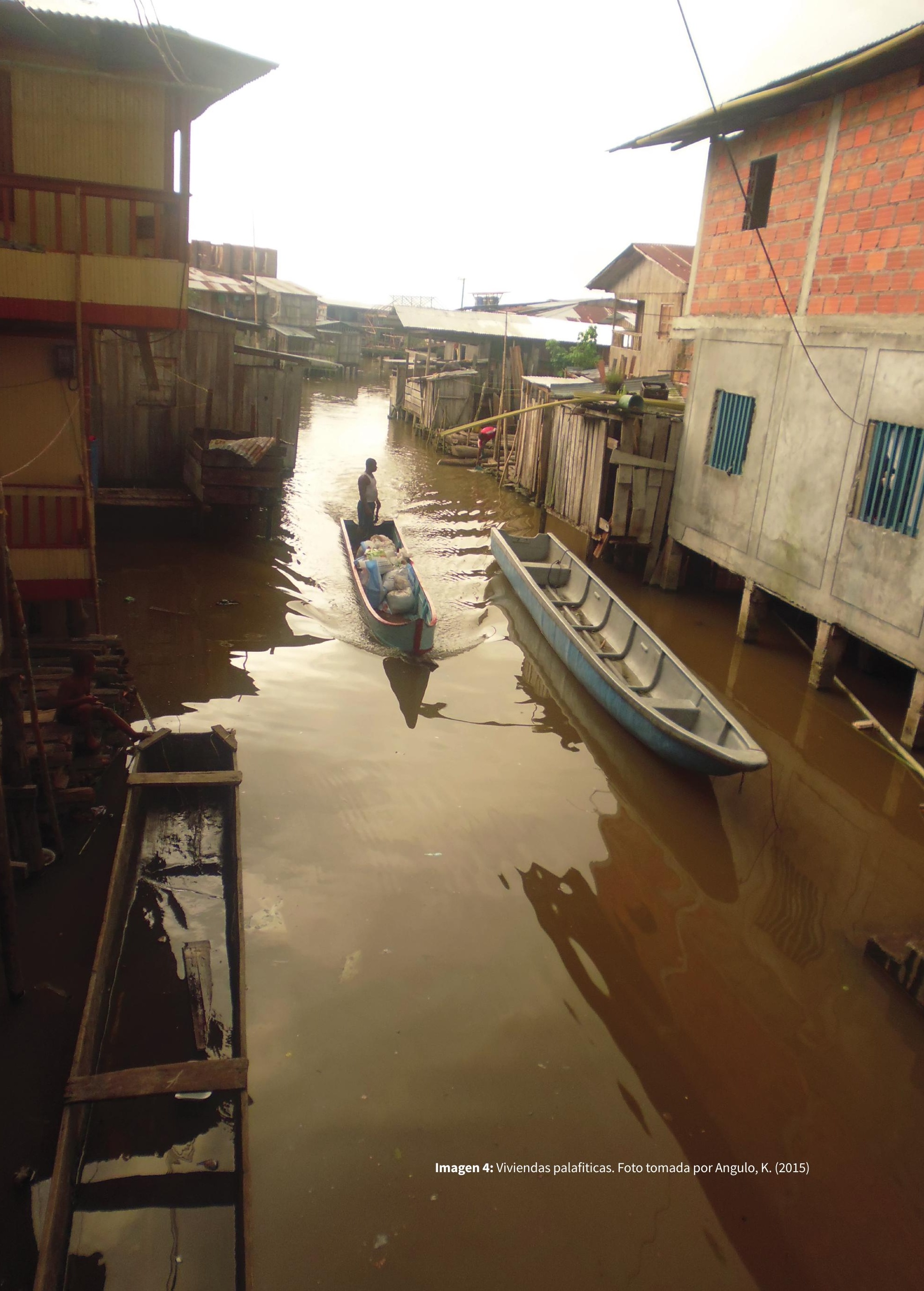


falta de sitios que recoja los elementos residuales, lo que conlleva a deshacerse de ellos arrojándolos al rio. Otra de las situaciones presentes en el municipio es la violencia y muertes causadas por el consumo excesivo de bebidas alcohólicas o por estar incluido en temas relacionados con el narcotráfico y grupos armados al margen de la ley.

Sin embargo, la comunidad afrocolombiana en el municipio Olaya Herrera vive su diariodía recobrando sus raíces ancestrales y su historia envuelta en "la música que es ante todo de percusión. Los instrumentos musicales más utilizados son el bombo, el guasá, la marimba y el cununo. Se baila el bambuco, la juga y el currulao" (Ilipac, 1997-2002; ver imagen 5 y 6). Su comida típica está ligada a la producción pesquera como la lisa, el pargo, la canchimala, el cangrejo, la jaiba, la piangua, almeja, entre otros, al igual que sus frutas como el naidí, naranja, caimito, guaba, sapote, y demás. Costumbres y tradiciones transmitidas a sus generaciones, eventos culturales prolongados año tras año vivenciadas a través del folclor, fiestas patronales, $y$ aquellos mitos y leyendas que desde hace tiempo vienen entablando relaciones en las voces y en el actuar de cada familia.

Por tal motivo, este proyecto investigativo, al igual que la práctica integral, fueron fundamentas y forjadas a partir de la importancia que tiene indagar y resignificar la memoria biocultural de las comunidades afrocolombianas del municipio Olaya Herrera desde la pesca artesanal, con la vinculación y participación de los conocimientos que tienen los estudiantes del grado cuarto (ver imagen 7), a partir de las experiencias que han desarrollado y que han obtenido desde lo que viven y el entorno en el cual se encuentran. La Institución Educativa Comercial

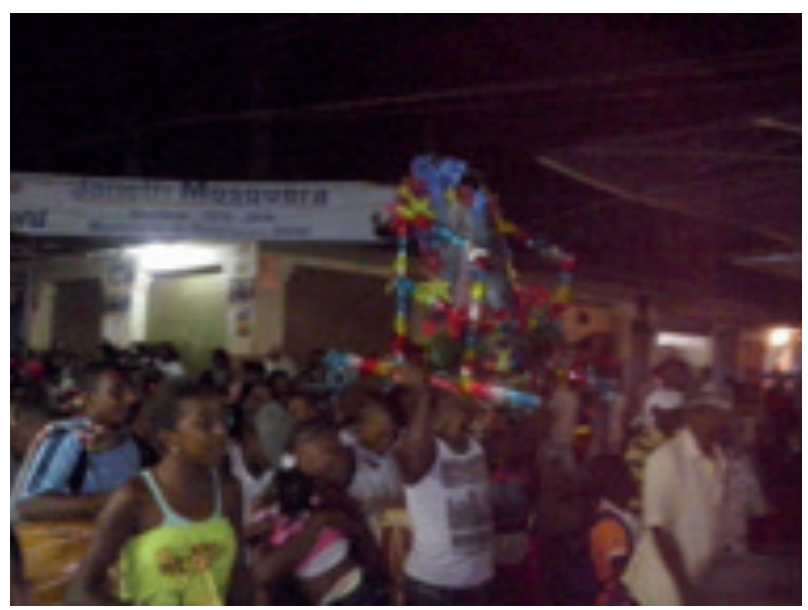

Imagen 5: Fiesta patronal del Señor de la Misericordia. Foto tomada por: Angulo, K. (2015)
Litoral Pacífico (Inelpac; ver imagen 8) está encaminada en formar personas íntegras con capacidad de enfrentar con objetividad, responsabilidad y respeto los cambios y retos que se presentan en la realidad actual, fomentando valores morales, culturales, sociales, democráticos y participativos; que sean útiles para la sociedad y le propicien su propio desarrollo. Esto se da con el fin de que las comunidades participen de una manera real y efectiva en el avance de la educación colombiana pertinente a su región para el mejoramiento de la calidad de vida de sus habitantes. Así, se busca contribuir a la formación de estudiantes como seres pensantes y creativos, que sean el fundamento de una nueva cultura ciudadana más justa, más ética, más solidaria, más humanitaria, participativa y más productiva sin pretender desconocer la riqueza étnica y cultural que le pertenece como a la comunidad como fruto de su propia historia”. (Ilipac, 1997-2002).

El propósito es, entonces, recobrar la importancia que tiene conocer, reflexionar y apropiarse del contexto posibilitando un proceso de cambio social y transformación de la calidad de vida de las futuras generaciones en las diferentes zonas del país. De tal manera, es importante entrar a indagar sobre las concepciones que tienen los estudiantes del grado cuarto acerca del propio reconocimiento que tienen de su contexto y el posicionamiento que van adquiriendo a través de sus mismas experiencias, con el fin de comprender que son sujetos que pertenecen a una sociedad que está implicada en un devenir de situaciones que los configuran diariamente y por lo tanto van direccionando la identidad de cada uno de los estudiantes, y por lo tanto de sus familias. Las personas son capaces de dar sus propias opiniones; son responsables, creativas, participativas y constantes en el proceso

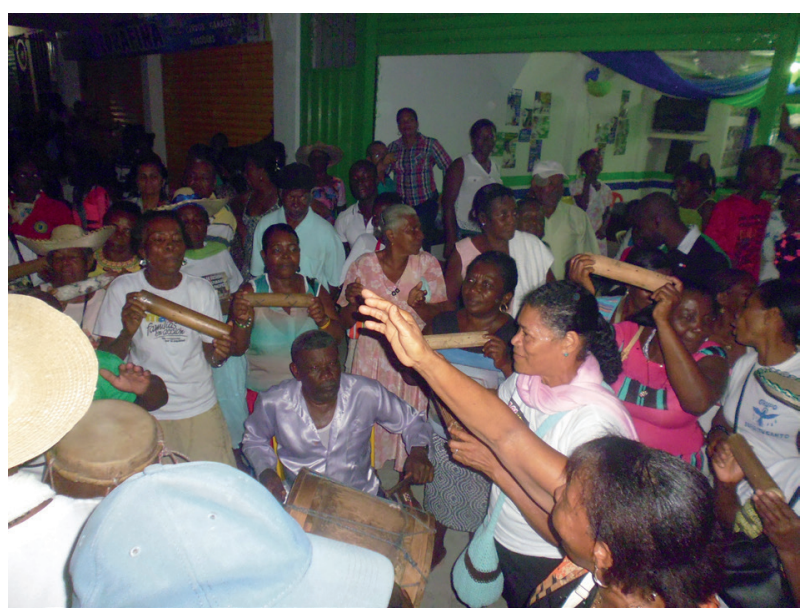

Imagen 6: Cantos e instrumentos afrocolombianos. Foto tomada por: Angulo, K. (2015) 
de práctica, permitiendo que se reconozcan a sí mismos, de tal manera que se construyen en conjunto estrategias didácticas en torno a la enseñanza-aprendizaje de la biología acorde con las necesidades, particularidades y realidades del contexto y la memoria biocultural asociado

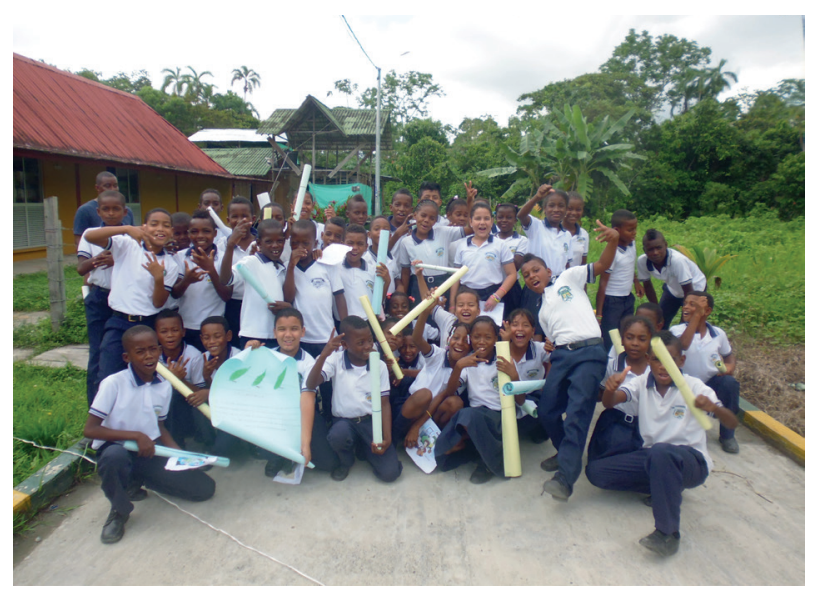

Imagen 7: Estudiantes de grado cuarto de primaria (INELPAC) Foto tomada por: Angulo, K. (2015)

\section{Metodología}

Para el desarrollo y obtención de información para el proyecto investigativo de la práctica integral en el municipio Olaya Herrera se tuvo en cuenta la participación de los estudiantes de cuarto grado del Inelpac, así como la de maestros de la institución y habitantes de la comunidad (padres de familia, pescadores y algunos taladores de mangle). Se tomó principalmente el modelo pedagógico holístico transformador, que indaga las concepciones que poseen los estudiantes acerca de la memoria biocultural y de los conocimientos, prácticas y creencias asociados a la pesca artesanal en el municipio a partir de la enseñanza-aprendizaje de la biología. Este modelo, creado por Ian Francesco (2003), permite relacionar la vocación con la profesión, con el fin de generar y desarrollar actitudes que en el proceso de enseñanza- aprendizaje se llevan a cabo en la construcción de conocimientos, habilidades y destrezas, generando procesos de pensamiento y así cualificar desempeños y aportar nuevos métodos, técnicas y procedimientos para el mejoramiento de la formación de los estudiantes.

La Institución en Bocas de Satinga emplea distintas formas de enseñanza en maestros, estudiantes y comunidad, con el fin de mejorar la calidad educativa de la región; de tal manera que el alumno sea considerado como una unidad integrada, en la que sus dimensiones están en interacción permanente, lo que hace un activo protagonista a la pesca artesanal. Esto permite identificar y formular posibles soluciones a las problemáticas que se presentan en el contexto sociocultural desde el aula de clase y las mismas vivencias de los estudiantes.

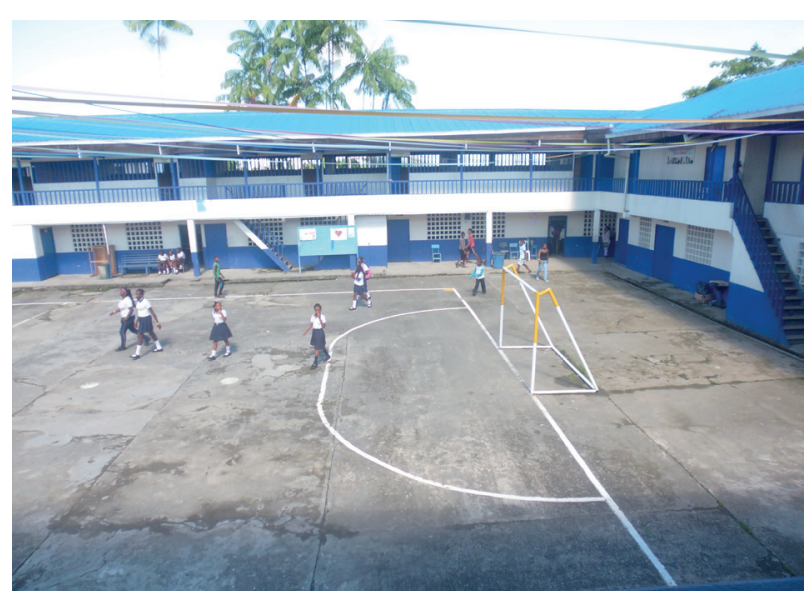

Imagen 8: Patio central (INELPAC). Foto tomada por: Angulo, K. (2015)

de su propio proceso de aprendizaje, que participa en todo momento, plantea preguntas, dudas e inquietudes, y el docente lo orienta en su búsqueda de saberes. Por lo cual, el rol del docente toma una posición de guía en el que ayuda al alumno al emprendimiento de su búsqueda de datos, según los intereses afectivos y cognitivos. El docente ya no impone su saber, sino que es un orientador que acompaña el proceso de aprendizaje (Francesco, I. 2011), para darle coherencia a los procesos de relación ser, saber y saber- hacer; además, el educando adquiere actitudes socioculturales en la construcción de conocimiento desde estrategias para el aprendizaje significativo, autónomo y colaborativo para la transformación de una realidad en contexto.

Con esto, se hizo importante fomentar el desarrollo de la investigación a partir de la construcción de conocimiento mutuo desde la implementación de actividades tales como dibujos de sus mismas experiencias y expectativas, así como escritos que permitieran consolidar la relación y las concepciones que tienen los niños respecto a sus saberes tradicionales, que es una parte importante de una tradición histórica afrocolombiana solidificada. Por esto, la investigación está estrechamente ligada a la vida intelectual, tecnológica, social, cultural y común del ser humano, que se constituye en un factor inseparable de cualquier actividad cognoscitiva u operación mental que se realice (...), ya que la investigación en la práctica se ha constituido en un camino para conocer la realidad 
y un procedimiento reflexivo, sistemático, controlado y crítico que ha posibilitado interpretar los hechos y fenómenos, relaciones y leyes, plantear problemas y buscar soluciones, y en general prepara el camino y crear las condiciones para estos cambios y transformaciones. (Cerda, 1993, p.15).

Esto ha causado gran impacto en las propuestas y el desarrollo de las diferentes actividades realizadas con los alumnos.

Este aspecto posibilita la responsabilidad y el compromiso que la investigación conlleva, abriendo un campo de búsqueda de sentido y de verdad halladas en el camino. El análisis y aplicación en la investigación cualitativa, según Baéz y Tudela, 2009, es aquella que produce datos descriptivos (las propias palabras de las personas, habladas o escritas y la conducta observable), entendiendo, además, desde la perspectiva de Martínez (2006) que "el enfoque cualitativo no tiene pretensiones de alta generalización de sus conclusiones, sino que, más bien, desea ofrecer resultados y sugerencias para instaurar cambios en una institución" (p.8). Para la obtención de resultados y análisis se hizo necesario relacionar los objetivos que desea cumplir la institución con los del modelo pedagógico holístico transformador y el enfoque cualitativo, ya que en conjunto se quiere lograr que los estudiantes de cuarto grado sean innovadores y por lo tanto esos conocimientos adquiridos los puedan comprender y emplear para su vida diaria; así, lograr cambios importantes en la comunidad educativa en general. Para ello, es necesario emplear distintas técnicas e instrumentos que contribuyeran a la recolección de la información y su posterior sistematización (ver tabla 1 y 2).

Tabla 1. Matriz de escritos y dibujos

\begin{tabular}{|c|c|c|c|}
\hline \multicolumn{4}{|c|}{ Nombre de la categoría } \\
\hline $\begin{array}{l}\text { CODIGO FUENTE } \\
\text { Nombre del grupo }\end{array}$ & $\begin{array}{l}\text { 옥 } \\
\text { 믐 }\end{array}$ & $\begin{array}{l}\text { DESCRIPTOR } \\
\text { Lo que los } \\
\text { estudiantes } \\
\text { dicen sobre } \\
\text { el dibujo }\end{array}$ & $\begin{array}{l}\text { COMENTARIO } \\
\text { INTERPRETATIVO } \\
\text { Descripción } \\
\text { interpretada de } \\
\text { los dibujos de los } \\
\text { estudiantes }\end{array}$ \\
\hline
\end{tabular}

Tabla 2. Matriz de entrevistas Fuente: elaboración propia

Nombre de la categoría (Para entrevistas)

\begin{tabular}{|c|c|c|c|}
\hline $\begin{array}{l}\text { Código Fuente } \\
\text { Nombre de los } \\
\text { grupos }\end{array}$ & $\begin{array}{l}\text { Descriptor } \\
\text { "Textual } \\
\text { lo de los } \\
\text { estudiantes } \\
\text { dicen" }\end{array}$ & $\begin{array}{l}\text { Código } \\
\text { Analítico } \\
\text { palabra clave }\end{array}$ & $\begin{array}{l}\text { Comentario } \\
\text { interpretativo, } \\
\text { interpretación } \\
\text { vertical de los } \\
\text { descriptores }\end{array}$ \\
\hline
\end{tabular}

En primer lugar, se empleó la técnica etnográfica para el proyecto de práctica integral, j'trabajo de campo', y cuyo resultado se emplea como evidencia para la descripción, en donde los actores son los privilegiados para expresar en palabras y en prácticas el sentido de su vida, su cotidianeidad" (p.12). Encaminando desde un primer momento la observación participante que ubica al investigador en medio de la comunidad que se está estudiando, el observador se integra a la comunidad con el fin de hacer parte de ella y poder encontrar más información verídica y recolectar datos con los instrumentos que son piezas fundamentales que se utilizan para registrar hechos, acontecimientos, sucesos utilizados para la sistematización de la información como el cuaderno de campo, cámara fotográfica y algunos registros manuales que se recogieron de los estudiantes. Se recolectó la información obtenida a través de medios como matrices de análisis categorial adaptadas de Peña (2013) que permitieron englobar los datos de forma sistémica.

Se utilizó la entrevista como un instrumento con el cual una persona (el investigador-entrevistador) obtiene información, interrogando a otra persona (entrevistado, respondiente, informante). Esta es una relación social a través de la cual se obtienen enunciados y verbalizaciones en una instancia de observación directa y de participación. (Guber, 2001). Se aplicaron algunas entrevistas semiestructuradas con el objetivo de determinar la información que se busca obtener a partir de preguntas abiertas a los estudiantes de cuarto grado, pescadores y padres de familia sobre algunas características principales acerca de aspectos sociales, culturales y políticos que identifican a la comunidad. Por otro lado, se identificaron problemáticas ambientales relacionadas con el rio, la pesca y tala de mangle y las concepciones que se tienen acerca de la memoria biocultural, con el fin de que el análisis pueda aclarar, mostrar y evidenciar aspectos importantes y característicos del contexto y las situaciones que se presentan en su comunidad (Pelaéz et al., s.f.).

Teniendo en cuenta que para este trabajo de investigación fue fundamental el apoyo y la colaboración de los actores locales del municipio, personas de la comunidad, padres de familia y trabajadores en algún campo relacionado con el medio ambiente, que dieron aportes importantes en el reconocimiento y apropiación del lugar en el cual se encuentran; así mismo fue la participación y ayuda de los 48 estudiantes del grado cuarto de primaria, quienes en su mayoría son de procedencia de la región Pacífica, aunque se encontraron niños originarios de otros lugares del país y dos estudiantes que hacían parte del Grupo Indígena Emberá, todos estaban conformados por 34 niños y 14 niñas (a quienes se les fue autorizado por sus padres de familia el uso de sus nombres para esta investigación) 
que con su capacidad de asombro y colaboración permitieron el desarrollo y la obtención de resultados en esta práctica integral II.

\section{Resultados}

En la enseñanza de la biología se hace importante articular los saberes tradicionales de una región con el conocimiento biológico que se van construyendo a través de los conocimientos adquiridos por la experiencia en la práctica integral II, de tal manera que estos puedan integrarse relacionando los diferentes aspectos que intervienen directamente en la población. Esto permite comprender que son sujetos que pertenecen a una sociedad que está implicada en un devenir de situaciones que los configuran diariamente y por lo tanto van direccionando la identidad de cada uno de los estudiantes y de sus familias, por lo que se hace necesario reconocer en la escuela las diferentes situaciones que modifican en su gran mayoría el diario vivir en Bocas de Satinga.

Así mismo, en este trabajo investigativo se llevaron a cabo fases que permitieron obtener diferentes perspectivas, concepciones y conocimientos acerca de la memoria biocultural asociada a la pesca artesanal en Bocas de Satinga, al involucrar a los estudiantes de cuarto de la institución y con la realización de preguntas orientadoras y dibujos realizados por ellos mismos, visualizando opiniones y experiencias de su entorno, sistematizando la información recolectada en matrices categoriales (ver tabla 1y 2). Además, se pudo incluir a los demás actores municipales que hacen parte de la cabecera municipal (personas del municipio, adultos mayores, padres de familia, trabajadores enfocados en la pesca y en la tala del mangle), a partir de la realización de entrevistas, las cuales se analizaron, comprendieron y reflexionaron según las vivencias del contexto.

\section{Fase I}

En esta primera fase con los estudiantes de cuarto grado de primaria de la Institución Educativa Comercial Litoral Pacífico (Inelpac) se inició con un proceso de observación participante dentro del aula, conociendo actitudes, comportamientos y expresiones que surgieron y se evidenciaron en ese primer momento. De igual manera se realizó una socialización del proyecto de práctica con los estudiantes para el conocimiento sobre las razones de su participación en el proyecto y de los temas principales que se irían a trabajar en las diferentes actividades con ellos, posteriormente se conformaron ocho grupos y cada uno estaba identificado por el nombre de un pez, que ellos anteriormente habían mencionado en una actividad "rompe hielo"; las personas que mencionaron el mismo pez fueron integradas en el mismo grupo (ver tabla 3). Esta actividad generó motivación para la participación individual y colectiva en la implementación de actividades como preguntas relacionadas con datos personales y su diario vivir, desarrollando así capacidades de integración entre los estudiantes y el maestro en formación.

Tabla 3. Grupos conformados por los estudiantes Fuente: elaboración propia

\begin{tabular}{|c|c|c|c|}
\hline 1. Grupo Pargo & $\begin{array}{l}\text { Mariana } \\
\text { Luz Dori } \\
\text { Juan Camilo } \\
\text { Edward } \\
\text { Maicol } \\
\text { Neison }\end{array}$ & 2.Grupo Canchimala & $\begin{array}{l}\text { Anyeli } \\
\text { Sahday } \\
\text { Estiven } \\
\text { Raul } \\
\text { Gabriel } \\
\text { Carlos }\end{array}$ \\
\hline 3. Grupo Lisa & $\begin{array}{l}\text { Ricardo } \\
\text { Dayana } \\
\text { Sebastian Vallecilla } \\
\text { Wilber } \\
\text { Jorge } \\
\text { Yasuri }\end{array}$ & 4. Grupo Gualajo & $\begin{array}{l}\text { Sebastian Cifuentes } \\
\text { Mayileth } \\
\text { Roci } \\
\text { Esteban } \\
\text { Yiber }\end{array}$ \\
\hline 5. Grupo Tilapia & $\begin{array}{l}\text { Samuel Peña } \\
\text { Estefany } \\
\text { Luis Eduardo } \\
\text { Fabian } \\
\text { Wilson }\end{array}$ & 6. Grupo Corvina & $\begin{array}{l}\text { Esteban Paredes } \\
\text { Clarisa } \\
\text { Sebastian } \\
\text { Andres Camilo } \\
\text { Rafael }\end{array}$ \\
\hline 7. Grupo Mojarra & $\begin{array}{l}\text { Juan David } \\
\text { Milton } \\
\text { Pilar } \\
\text { Yadira } \\
\text { Daniel }\end{array}$ & 8. Grupo Bacalao & $\begin{array}{l}\text { Isamar } \\
\text { Edwin } \\
\text { Kiara } \\
\text { Jesus } \\
\text { Alexys } \\
\text { Anderson }\end{array}$ \\
\hline
\end{tabular}


Entre tanto, gran parte de los trabajos recibidos y posteriormente sistematizados en matrices categoriales adaptadas de Peña (2013; ver tabla 1 y 2) dieron cuenta de ese enriquecimiento cultural que tienen los niños acerca de la memoria biocultural y sobre una de las actividades económicas más realizadas en la región, como es la pesca artesanal en la población, de la que surgieron los siguientes interrogantes: ¿Qué es la pesca artesanal? ¿Cómo se realiza? ¿Qué elementos son utilizados para la actividad? ¿Qué experiencias han tenido con la pesca? ¿Qué aspectos contribuyen y afectan la pesca artesanal en el municipio?, entre otras. A partir de este proceso investigativo, se pudo conocer a los estudiantes, seguido de trabajos grupales e individuales en las que incluyeran dibujos de acuerdo con lo que veían e imaginaban de la memoria biocultural y la pesca artesanal en Bocas de Satinga, encontrando que son muy pocos los estudiantes que desconocen los términos debido a las costumbres y hábitos obtenidos en su contexto. A causa de ello se obtuvieron conocimientos, prácticas y creencias relacionadas con la memoria biocultural del lugar asociado a la pesca artesanal.

Las actividades planteadas y ejecutadas orientaron la práctica con miras a la apropiación de los saberes y de la diversidad biocultural del contexto regional afrocolombiano; encontrando diferentes conocimientos y perspectivas de lo que para ellos es la pesca artesanal:

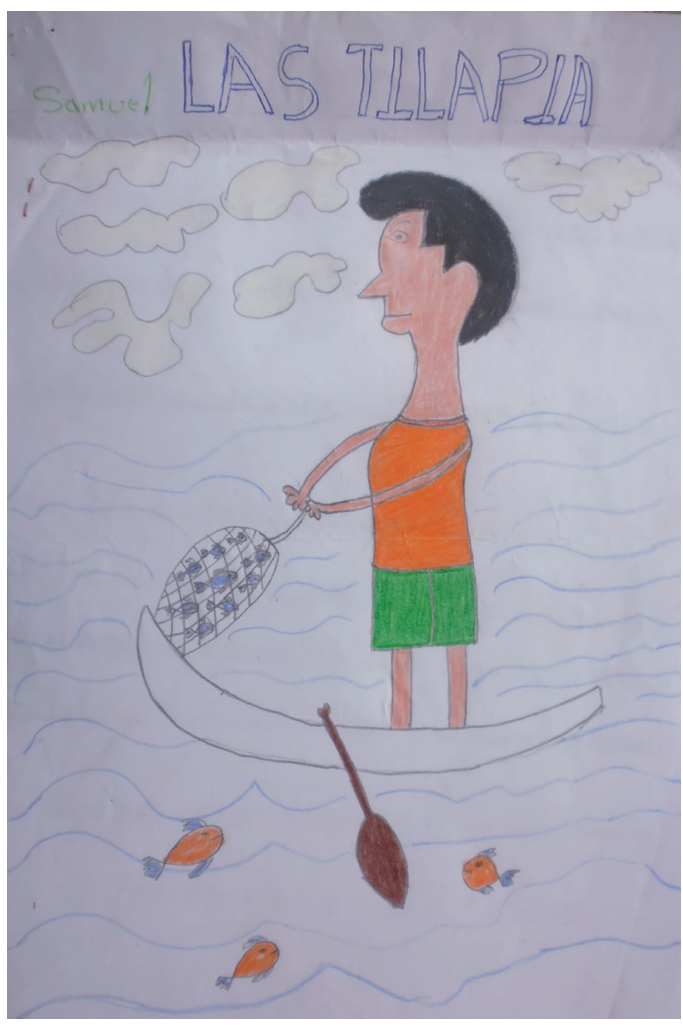

Dibujo 1: Realizado por Grupo Tilapia. (2015)
- "Es cuando pescan pescados como: la lisa y el gualajo". Kiara Padilla.

- "En donde muchas personas van al mar a pescar". Esteban Alegria.

- "Para mí la pesca es que uno puede demostrar lo que hace". Anderson Chirimia.

- "Para mí la pesca artesanal es coger pescados como el bacalao, la lisa, etc. Para comer". Mariana Ballesteros.

- "La pesca artesanal es cuando una persona saca un marisco del agua". Jhoan Cifuentes.

Fue importante identificar en los estudiantes que la pesca artesanal es un lenguaje que para ellos, desde un principio, fue comprensible debido a que es un aspecto que tienen gran influencia en la comunidad, y que hacen parte de su cotidianidad y su contexto, manifestándolo en los conocimientos y en las experiencias mencionadas anteriormente y que reflejan las distintas formas, épocas, medios para su extracción que influyen y dinamizan la productividad, su consumismo y por lo tanto su cuidado para el ambiente. Por otro lado, se tuvo en cuenta la dificultad que se presentó en comprender la significación de la memoria biocultural en su entorno, lo que abrió paso a la realización de actividades y estrategias didácticas que permitieran conocerla ya que es parte importante de este proyecto a partir de la realización de cuentos, historias que evocan recuerdos de ellos mismos. Todo esto se realizó con el objetivo de identificar con el tiempo recuerdos pertenecientes a la región y a su territorio, lo que complementó y enriqueció el proceso cultural, educativo y biológico de todos.

En un segundo momento se indagaron las prácticas relacionadas con la pesca artesanal que mencionaron los estudiantes; estas fueron guiadas especialmente hacia los elementos que utilizan para la realización de esta actividad:

- "La pesca es cuando uno sale en su potrillo con su atarraya a agarrar pescado". Samuel Peña (2015, Bocas de Satinga)

- "La pesca artesanal es cuando las personas van hacia el rio a pescar con su anzuelo o con atarraya". Esteban Paredes. (2015, Bocas de Satinga)

- "Llevan en una canoa maya, nailon, anzuelo para agarrar los pescados para comer". Dayana Linares. (2015, Bocas de Satinga)

- "En donde muchas personas van al mar a hacer un trabajo de pesca para el sustento de su familia". Isamar Valencia. (2015, Bocas de Satinga)

- "La pesca se hace con una caña de pescar y se puede poner cualquier clase de carne. Se tiene que hacer en un ligar cerca del rio. Se pesca cualquier 
tipo de marisco cerca al rio. La mayoría pescan con cañas de pescar pero también se pescar con palos o varillas". Grupo Gualajo. (2015, Bocas de Satinga)

Muchos de los estudiantes dieron a entender y conocer principalmente aquellas herramientas que son utilizadas en la pesca artesanal actualmente (ver dibujo 2 y 3 ) y que desde hace mucho tiempo se vienen manejando, aunque desde hace unos años se han implementado métodos

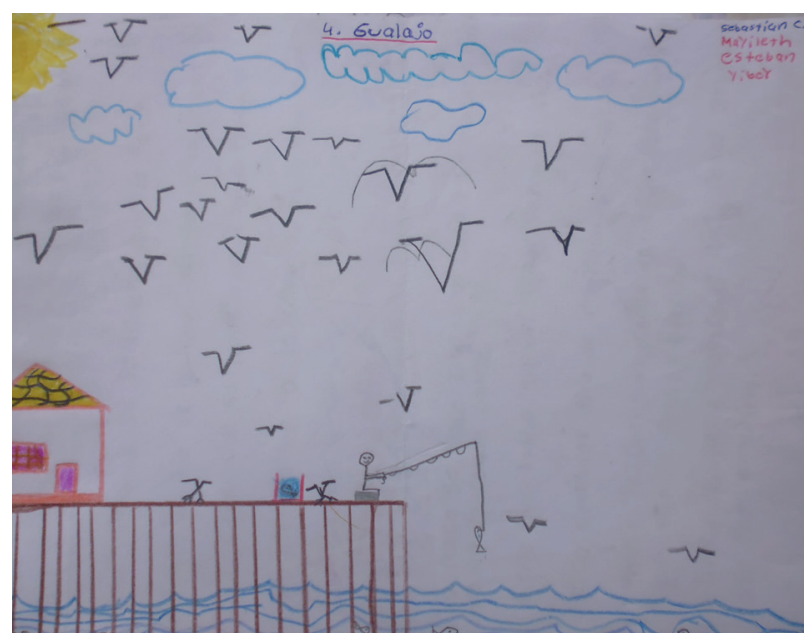

Dibujo 2: Realizado por Grupo Gualajo. (2015)

Por otra parte, se mencionaron aquellas acciones de la comunidad que perjudican el cuidado del ambiente en la zona, como la contaminación presentada por arrojar basuras en las calles y en el rio, afectando la salud de los seres vivos en el lugar debido al difícil acceso en algunas zonas del municipio al basurero principal y que causa enfermedades en los habitantes. A su vez, esto imposibilita el uso del agua de rio y reduce cada vez más otro recurso natural del país, como se puede ver en un dibujo que consistía en representar cómo era Satinga hace 50 años y cómo será en los próximos 20 años (ver dibujo 4). Otras situaciones nombradas por los estudiantes son las que se presentan en la comunidad y que hacen parte de una memoria biocultural, no solo afrocolombiana sino colombiana, que se viven en otras partes del país desde hace muchos años, como la violencia, que impactan y hacen parte de aquellos aspectos que no les gusta de Bocas de Satinga, pero que hace parte de las vivencias que se presencian en la comunidad. Un ejemplo de esto es lo que mencionó un alumno: "No me gusta Satinga porque matan a gente inocente, porque hay mucho peligro, es muy violento" (Edwin Caicedo, 2015). Este es un testimonio frecuente entre los estudiantes y padres de familia, incluyendo otros factores como la inseguridad, el ruido, cargar agua, etc. como la changa, el puntero, el chinchorro, el torpedo o dinamita, (esta última que es la más contaminante). Estos generan e inician un proceso de impacto sobre los recursos hidrobiológicos de la zona, con el aumento de uso de tecnología inapropiada, como redes de arrastre, que generan un paulatino cambio en la oferta natural de estos recursos, acabando con toda la diversidad de peces que existen en el rio y en el mar. (Ministerio del Ambiente, 2007a).

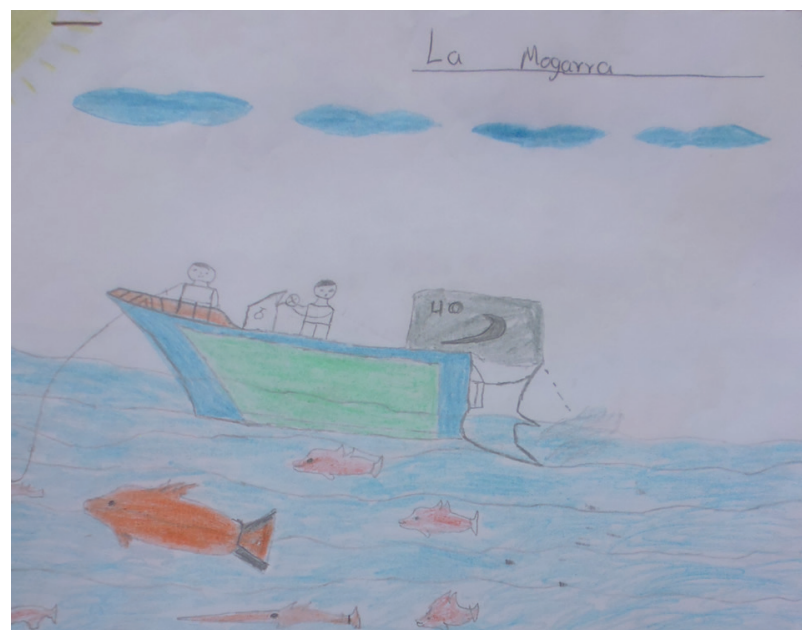

Dibujo 3: Realizado por Grupo Mojarra (2015)

Por último, se encontraron diversas creencias existentes en los estudiantes (mitos, leyendas e historias) en relación a la actividad económica de la pesca artesanal y sobre el municipio:

- "Un señor eran las cinco de la tarde y el decidió quedarse hasta la noche cuando de repente él quería irse cuando de repente la canoa se le va de lado y el cae al agua y la madre agua se lo llevo". Grupo Corbina. (2015, Bocas de Satinga)

- "Los pescadores no pueden salir de noche a los ríos porque alguna visión puede jalarlo al agua y ahogarlo. Por eso los pescadores no salen a pescar de noche por la visión llamada madre agua". Grupo Bacalao. (2015, Bocas de Satinga)

Estos relatos nombrados por los estudiantes dejan ver que la realidad va más allá de lo que se vive a diario, que algunos hechos trascienden a esa memoria biocultural alojada en los hogares satingueños, y que es transmitida de generación en generación permitiendo entablar relaciones y dar respuesta al significado que tiene la pesca artesanal en Bocas de Satinga. De este modo, se vio la necesidad de retroalimentar el proceso con los estudiantes en el que 


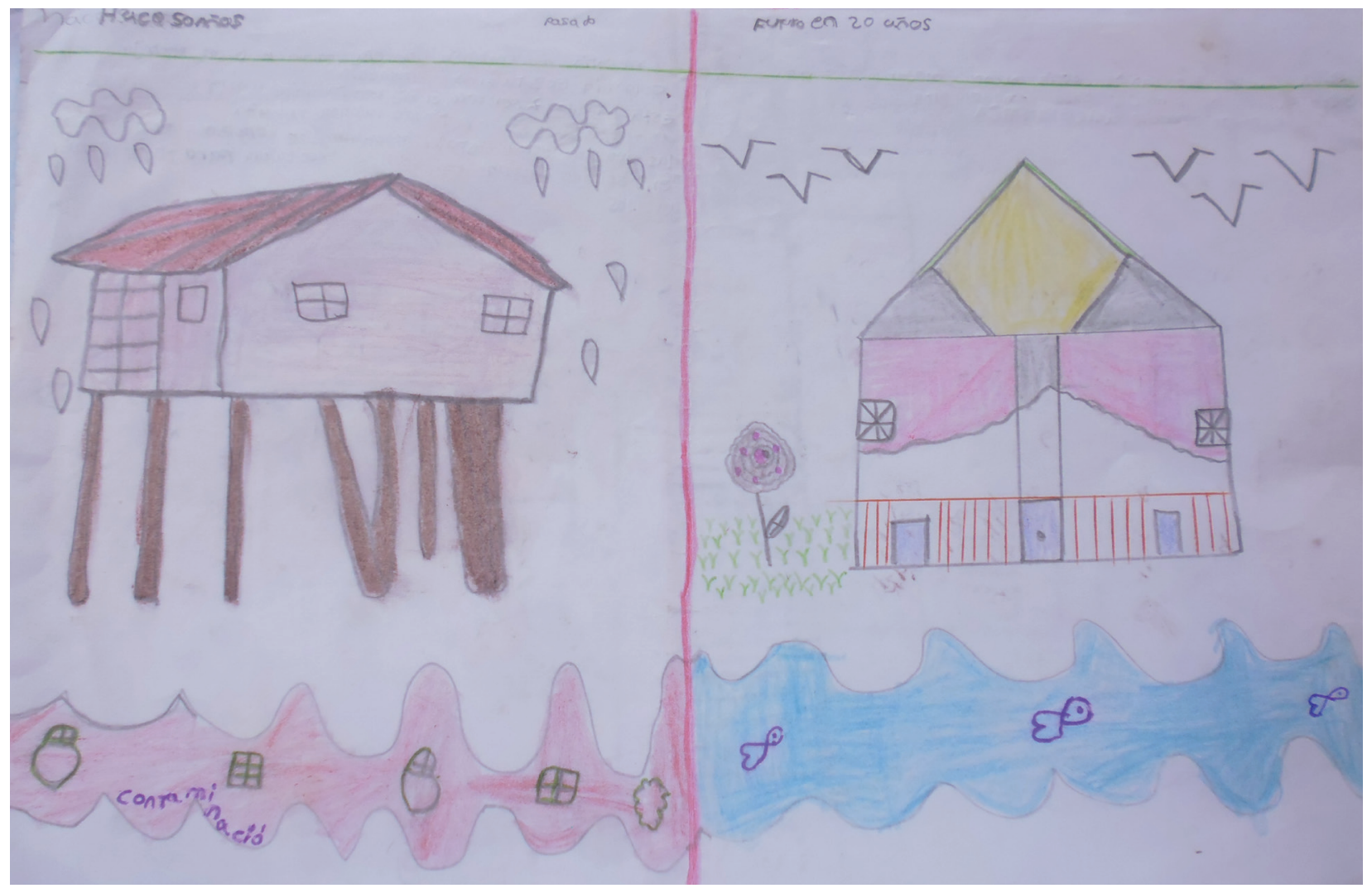

Dibujo 4: Bocas de Satinga hace 50 años y en los próximos 20 años. Realizado por Dayana Linares (2015)

surgieron nuevos mitos, de los cuales no se comentaron en los trabajos entregados; algunos de esos mitos fueron:

- Cuando los pescadores salían en las noches a pescar encontraban un barco que les daba luz, pero esa luz desaparecía y aparece en otro lugar, haciendo que los pescadores que las seguían se perdieran en alta mar y a veces se perdían y no se volvía a saber de ellos.

- Mujeres hermosas con cabellos largos que jalan y envuelven y envuelven a los pescadores hacia el fondo del agua, algunos de sus nombres son: "la chola", "la cucuragua", y una mujer que tiene forma de sombrilla se llama la "madre agua".

- La Tunda que es una mujer que se le aparece a la gente que se transforma en forma de alguna persona conocida para ellos una de sus patas tiene forma de remolino, ella se lleva a las personas y las hace perder; para rescatarlas, hay que buscarlas con el padrino, la madrina, Bombo, Cununo y Guasa y se reza el Padre Nuestro y el Dios te Salve.

Estas declaraciones se pueden complementar con algunas opiniones e historias pertenecientes a los padres de familia acerca del inicio, cambios y problemáticas en el municipio de Olaya Herrera en Bocas de Satinga:

- "Satinga era un corregimiento de Mosquera y cuando los pobladores se dedicaron a liberarse de Mosquera y organizar su propio municipio porque se tenía mucha población eso es una historia de Olaya Herrera". Jhony Vallecilla. (2015, Bocas de Satinga)

- "Cuando el pueblo empezó a derrumbarse en aquel entonces se fueron muchas casas enteras al río por el derrumbe, también se derrumbó una obra muy importante en nuestro pueblo como lo era el acueducto, la biblioteca, el parque, el lugar de los ancianos". Marleny Obregon. (2015, Bocas de Satinga)

- "En el pueblo de Satinga uno se la pasa muy alegre, celebra las fiestas patronales y otras cosas, etc.". Marina Villa. (2015, Bocas de Satinga)

Todo esto permite englobar aquellos conocimientos, prácticas y creencias que poseen los estudiantes de cuarto grado y que permiten entender que son sujetos que se encuentran enmarcados dentro de un contexto de historias, hechos, cambios y factores que influyen sus 
formas de vida, y por lo tanto, sus comportamientos dentro de una sociedad. Ellos constituyen, cada vez más, las futuras generaciones de esas historias y acontecimientos que algún día fueron transmitidas, inculcadas y heredadas a nuestras familias y que hacen parte de la identidad del pueblo.

A través de este proceso formativo en la práctica, se realizaron diversas discusiones y socializaciones con los estudiantes, de modo que se permitiera construiry consolidar un significado propio acerca de la pesca artesanal y la memoria biocultural a partir de las experiencias adquiridas en el municipio:

Pesca artesanal: "Es una actividad en la cual los pescadores trabajan de manera artesanal sin maquinaria, sacando productos como peces, camarones, conchas, etc., para el autoconsumo". Estudiantes de cuarto grado de primaria, Profesor Marcial Vallecilla y Profesora en formación Karen Angulo. (2015)

La memoria biocultural: "que es la forma en la cual podemos recordar aquellas situaciones que hacen

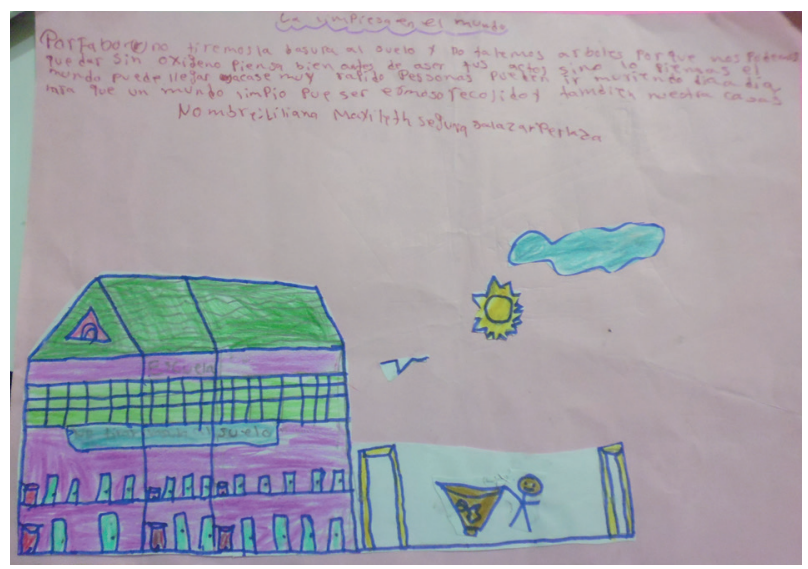

Dibujo 5: Pancartas de cuidado del ambiente. Realizado por Mayileth Segura. (2015)

\section{Fase II}

Con la obtención de resultados y análisis de la información a través de metodologías y técnicas en la práctica integral II, se realizaron algunas entrevistas semiestructuradas a varios actores locales (rector, maestros del Inelpac, funcionarios del pueblo, padres de familia, taladores de mangle y pescadores) que desde hace tiempo conocen las dinámicas que se han transformado a lo largo del tiempo dentro del municipio y que han permitido cambios en aspectos políticos, sociales, culturales, ambientales, entre otros. Estos acontecen dentro de la misma de un lugar propio y cómo a través de generación en generación podemos seguirlas recordando y realizando". Estudiantes de cuarto grado de primaria, Profesor Marcial Vallecilla y Profesora en formación Karen Angulo (2015)

Esos pensamientos y esas palabras de los estudiantes dan una idea propia de lo que significa una de las actividades más importantes de la costa Pacífica, y de la importancia que tiene la memoria para nosotros y para nuestro propio contexto, del que resurgen esas raíces afrocolombianas que identifican y hacen propia a una comunidad como lo es Bocas de Satinga, permitiendo que muchos estudiantes se integraran y dieran sus ideas y opiniones, para ser escuchados por sus compañeros junto con las opiniones y el acompañamiento del Profesor Marcial Vallecilla. Se finalizó con algunas actividades de reflexión acerca del comportamiento del ser humano con la naturaleza y las consecuencias que esto trae para el ambiente, a través de pancartas con mensajes y dibujos para hacer un llamado a la comunidad sobre él y la conservación de nuestro entorno (ver dibujo 5 y 6 ).

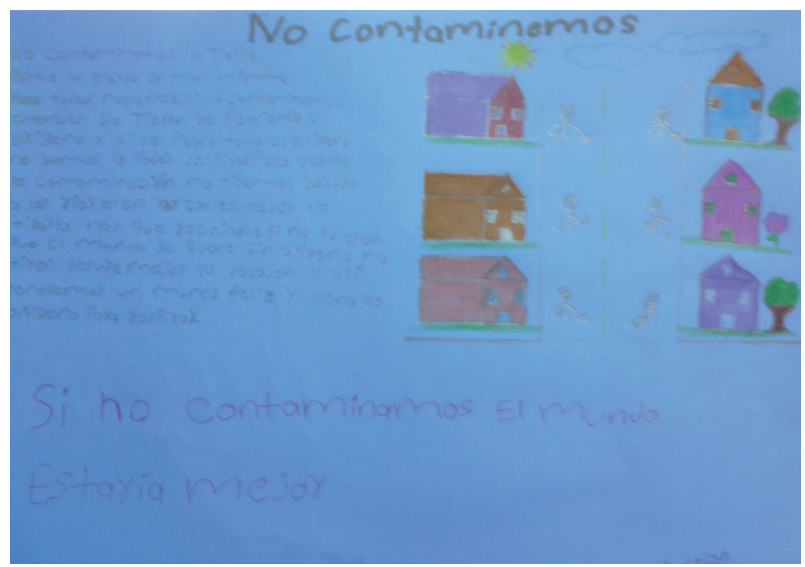

Dibujo 6: Pancartas de cuidado del ambiente. Realizado por Sebastian Cifuentes. (2015)

comunidad; a través del reconocimiento de los conocimientos, prácticas y creencias en cada uno de ellos con el fin de encontrar la importancia y el significado que le dan a la pesca artesanal en el municipio en algunos maestros. Sobre esto, es importante destacar el testimonio del rector Hugo Sánchez:

Es muy importante que nuestros estudiantes se fortalezcan, lo que tiene que ver con el conocimiento de la pesca ¿porque?, porque nuestra zona, nuestra región la gente dentro de su subsistencia depende de la pesca la gente vive de la pesca, uno de los potenciales nuestros

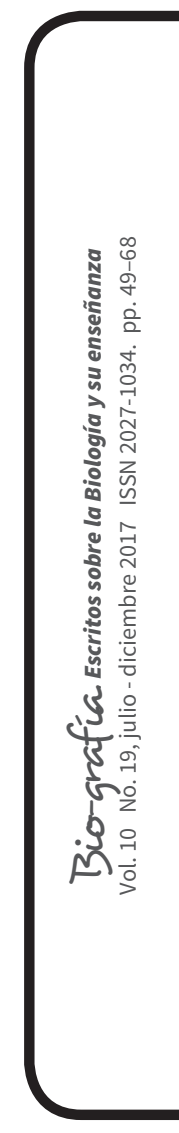


de acá es la pesca a la gente le gusta mucho lo que tiene que ver con la parte del pescado y desde acá se saca el pescado para llevarlos a las ciudades, por eso debemos conocer lo que son nuestros procedimientos para lo que tiene que ver con la pesca ¿en que nos beneficia la pesca?, de que toda nuestra zona de que la parte acuífera nuestras aguas sean limpias no haya contaminación. (Rector Hugo Alirio Sánchez. Licenciado en Ciencias Sociales y Economía, 2015, Bocas de Satinga).

Por lo cual, otras opiniones respecto a la pesca artesanal y al cuidado del medio se hicieron presentes en la gran mayoría de los entrevistados, dando a entender las problemáticas ambientales (ver imagen 9) que se presentan en la comunidad por falta de apropiación del mismo territorio, a partir de las herramientas y prácticas utilizadas para la realización de esta actividad económica y extracción del pescado en el municipio:

En cuanto a la pesca artesanal también siempre hay que educar para que las personas para que la pesca artesanal no se convierta en la pesca indiscriminada, porque talamos, acabamos y dejamos las especies en vía de extinción ¿porque? Porque como lo hacen artesanalmente no tienen unas armas técnicas para decir este pez si, este pez no, ellos echan unas redes o unas atarrayas que son las armas donde van a caer todos esos pececitos y caen peces pequeñitos pequeñitos que apenas nacieron hace tres días y cuando van a retirar las armas que son las redes, o son las atarrayas o son los anzuelos que es donde van a pescar estos dichos animalitos cuando vemos después del tiempo los que cayeron ya se ahogaron y entonces como no nos sirve para comer los botamos al mar petrificando y ahora si que hacemos, entonces contaminamos las aguas, viendo que el agua para ingerirlo debe ser incolora, insabora e inholora y ya le damos olor y ya le damos color, entonces no puede estar portable, entonces hacemos dos cosas contaminamos nuestras aguas ya no son aptas para ingerirlas y también estamos acabando con la especie. (Profesor Marcial Vallecilla. Licenciado en Ciencias Naturales, 2015, Bocas de Satinga).

Esto permite comprender el estado en el cual se encuentran las calles y los ríos y mares cercanos a este municipio, debido a ciertas acciones por parte de los habitantes que perjudican no solo el cuidado y la conservación del rio, sino la estabilidad de la salubridad de los seres vivos que habitan en la población. Por esto, se enfatiza cada vez más en la importancia que tiene recuperar y reconocer la memoria bicultural perteneciente a Bocas de Satinga: eso enriquece porque la memoria es recoger, recapitular..., porque es allí donde las personas se van a concientizar, es algo que a través de esto podemos obtener mucho bienestar... saber cómo vamos a manejar todos estos proyectos, todas estas vivencias porque si manejamos bien los manglares obtenemos muchos resultados de muchos mangles más y si manejamos bien la vivencia y la pesca artesanal obtendremos que nuestros hijos pueden conocer a muchas especies que hoy están en vía de extinción, porque a través de la memoria aprendemos a pedir alternativas de solución y alternativas de solución son resultados positivos que nos permiten proyectarnos no para hoy sino hacia más allá, para obtener un planeta o un ecosistema biodiverso. (Profesor Marcial Vallecilla. Licenciado en Ciencias Naturales, 2015, Bocas de Satinga).

Se recordó también aquellas prácticas y las formas de vida que anteriormente se daban entre los habitantes del pueblo y que se evidencian en ese sentimiento de apropiación del territorio que inicialmente se efectuaba:

Yo agarraba pescaditos con una cosita que se llamaba Chaya, la chaya es algo que se hace con un toldillo, entonces usted agarra su punta y yo mi punta y nos íbamos a la quebradita y la levantábamos y como un colador entonces eso sale harto camarón, ese camarón que usted ahora come, eso yo lo agarraba; o entonces era con un canasta que es con lo que hoy en día llevan y cogen los cangrejos, entonces se hace más grande porque es más grande, entonces una agarraba hasta con la mano, yo que vez agarre una culebra en la mano, y cogíamos peces, sapos y para nosotros era muy curioso, muy fantástico. (Profesora Marina Villa Franco. Licenciada en Educación Religiosa con énfasis en Ética y Valores, 2015, Bocas de Satinga).

Por otro lado, con las diversas actividades realizadas con los estudiantes, se plantearon algunas preguntas que permitieran incluir a los padres de familia en el proceso de conocimiento, prácticas y creencias que estaban desarrollando los estudiantes en la institución relacionado con la memoria biocultural, asociado a la pesca artesanal en la región a partir de las concepciones obtenidas a través de los años:

Anteriormente se pescaba con redes, ósea como mayadora, catangas y vara y que se pescaba, peces como barbudo, biringo, gualajo, canchimala, guacuco, boba, pargo, lisa, nato, jurel, burique, raya, tollo, tilapia, camarón, entre otros. (Ana Garcias. Madre de familia grado cuarto, 2015, Bocas de Satinga). 
3 
Anteriormente pescaban los adultos con vara y agarraban pescado llamado bocón, barbudo, rabiseco, sábalo y otros muchos más. (Inginio. Padre de familia del Grupo indígena Embera, 2015, Bocas de Satinga) (ver dibujo 7).
Pues se pescaba peces pero con un tamaño superior porque ahora los pocos que quedan son muy pequeños por el mal uso del petróleo, las fumigaciones, etc. (Ricardo Riascos. Padre de familia grado cuarto; 2015, Bocas de Satinga).

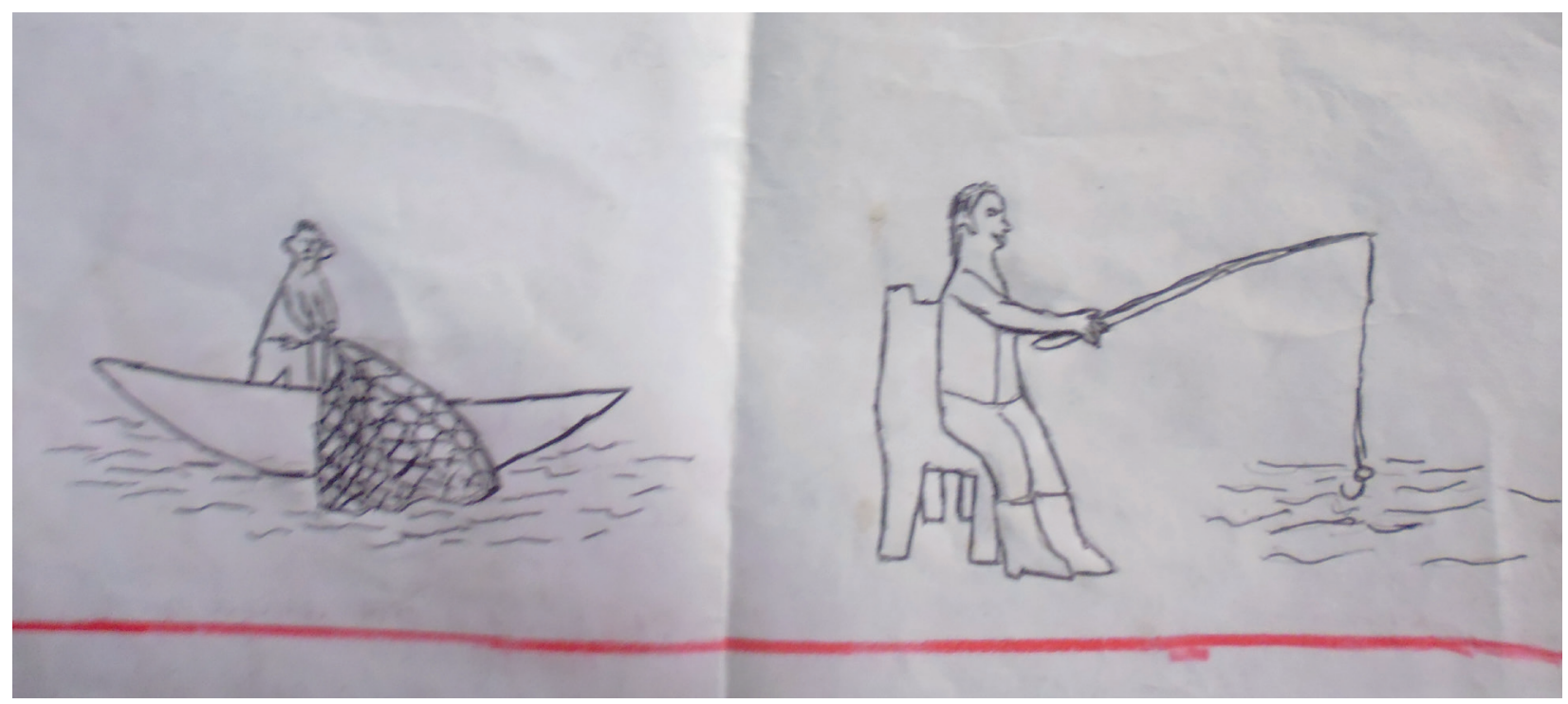

Dibujo 7: Pesca artesanal. Dibujo realizo por Inginio padre de familia del Grupo indígena Embera (2015)

Por último, se realizaron entrevistas a algunos pescadores lo que reforzó esos conocimientos, prácticas y creencias anteriormente mencionadas y permitió comprender el trabajo y la forma como lo realizan, recopilando sus saberes que han obtenido a través de su experiencia:

\begin{abstract}
En el momento de pescar la corvina uno sale a las 6:30 de la tarde a las 8:30, lo está levantando ahí cuando hay producción cada canoa de estas levanta 10, 15, 20 piezas corvina de 8 o 10 kilos, diferente es para los que camaronean, (...) por lo menos para los lados de Satinga, para abajo calabazal, cocal, utilizan mucho la maya de rifliyo que se dice eso es para los langostinos pequeños que se dice nacional, aquí se usa la dos y media y los dos tres cuartos, este es de 8 pulgadas es reglamentaria no la quitan en ninguna parte la 3 pulgadas tampoco la quita el medio ambiente, mientras que esa maya que usan por aya es perjudicial para el ambiente porque recoge peces muy pequeños, por lo que es muy pequeña aquí va con la fauna. (Pescador ilder Rodríguez de la Playa Amarales, 2015, Bocas de Satinga).
\end{abstract}

Al observar en este caso relatos originarios de las experiencias obtenidas de manera empírica y que han trascendido en las generaciones, se observaron las costumbres y su realización de manera artesanal en la región, para entablar una relación entre las prácticas, el ambiente y las concepciones que se tienen para el cuidado y conservación de las especies, empleando medidas de protección contra los peces y otros mariscos extraídos de los ríos y mares como los camarones, jaibas, conchas, etc. Estas ideas constituyen una estrategia de supervivencia que se ha venido realizando en la historia afrocolombiana desde hace mucho tiempo, no solo como una actividad económica sino también como sustento familiar.

Con esto, una mirada comparativa de los conocimientos, prácticas y creencias de los estudiantes de cuarto grado de la Institución Educativa Comercial Litoral Pacífico (INELPAC) y los demás actores que hicieron parte del desarrollo de la práctica integral II permitió encontrar en común aspectos que le dan significado, reconocimiento territorial y enriquecimiento a las diversas formas de realizar esta actividad, incluyendo los momentos, las herramientas y las extracciones de especies que influyen en la pesca artesanal y lo que da gran importancia al futuro progreso de la pesca y la reflexión acerca del cuidado del ambiente en la población. Así, hay que tener en cuenta las diferencias que no todos los habitantes reconocen sobre el deterioro causado por la contaminación de basura desmesurada, por la pesca indiscriminada y por lo tanto se siguen manteniendo este tipo de acciones dentro de la comunidad, lo que perjudica cada vez más ese 
enriquecimiento histórico alojado en los ancestros afrocolombianos y acabando con una de las formas de suplir las necesidades familiares que tienen los satingueños.

De esta forma, se llevaron a cabo cada uno de los objetivos proyectados, realizando actividades con los estudiantes que dieran cuenta de las problemáticas ambientales causadas por la contaminación del suelo, ríos y mares, desde la experiencia construida en la práctica integral, con el fin de ver la importancia que tiene cuidar y conservar el ambiente, y así generar conciencia y voluntad de cambio. Esto aporta reflexiones pedagógicas desde el proyecto investigativo que contribuyen a la enseñanza-aprendizaje de la biología, a partir de la memoria biocultural asociada a la pesca artesanal en la institución Educativa Comercial Litoral Pacífico, lo que permite reconocer procesos adecuados para la enseñanza-aprendizaje en un área rural desde la diversidad biocultural.

Por tal razón, como futura licenciada en biología, a través de las experiencias, conocimientos y perspectivas adquiridas durante la práctica integral, veo la importancia que tiene reconocer un contexto y las interrelaciones que deben existir entre lo biológico y lo social en el ser humano, el cual tiene un papel fundamental como constructor y reconstructor de cultura, que determina aquellos conocimientos, prácticas y creencias a tener en cuenta que inciden en las representaciones, acciones y pensamientos sobre el ambiente y su entorno. Esto es fundamental para comprender la búsqueda de sentido acerca de la vida y lo vivo en un territorio que hará parte del contexto y por ende constituirá la identidad de cada uno de los individuos y de su comunidad.

\section{Conclusiones}

Con respecto a este trabajo investigativo realizado a través de la práctica integral II en Bocas de Satinga, se permitió evidenciar y enriquecer algunas de las dinámicas presentadas en el municipio, que dieron lugar a conocimientos, prácticas y creencias relevantes en sus habitantes al encontrar relación entre lo manifestado por los estudiantes de cuarto grado y los actores locales con las metodologías y referentes conceptuales planteados inicialmente. Esto permitió concebir la importancia que tiene preservar la memoria biocultural afrocolombiana en las futuras generaciones con el fin de impartir conocimientos y concepciones ancestrales y la pesca artesanal en la comunidad, vista como una actividad económica que merece gran respeto y cuidado y por la que dependen en su gran mayoría las familias del municipio.

El municipio de Olaya Herrera en Bocas de Satinga se caracteriza por tener personas alegres, de costumbres afrocolombianas con un folclor lleno de colores, olores y sabor que apropian a la comunidad aún más a sus raíces a través de toques de instrumentos como el cununo, el guasá, la marimba, el bombo y el canto de mujeres con su voz aguda que transportan a otras dimensiones negras a sus pobladores, por medio de festividades y fieras patronales característicos de la costa Pacífica y sin perder de vista sus comidas típicas integradas de mariscos extraídos de los mares o ríos cercanos de la región.

Estos recursos naturales que predominan en la región forman parte de una historia que conlleva diversos caminos de raíces afrocolombianas, que dan lugar a que los pobladores se conecten con los beneficios que estos traen para el municipio; sin embargo, se hace importante que los habitantes de las comunidades cercanas a estos territorios se concienticen de las problemáticas ambientales que están aumentando y, por lo tanto, disminuyen los recursos que identifican y hacen propios a la comunidad, sin dejar de lado esas riquezas y saberes que se poseen desde los ancestros y prolongan aquellos hechos y costumbres que hoy en día muchos conocen y pocos practican.

Entendiendo que en el pasado predominaba la pesca artesanal no contaminante, hoy en cambio prácticas como la changa, el puntero y el chinchorro acaban con toda la diversidad de peces y conchas existentes. Las prácticas antiguas, permitían no solo el aprovechamiento y el sustento de las familias, sino que además propendían por el cuidado de los huevos y de otras especies. Aún con lo anterior, ya desde tiempos pasados se evidenciaba el uso de técnicas poco adecuadas y además peligrosas para la vida (Ministerio del Ambiente, 2007a).

La comunidad presenta dificultades y problemáticas de tipo ambiental en el cual los residuos son arrojados al rio y al suelo, lo que incrementa la contaminación en el municipio por parte de la misma población y el desprendimiento y la falta de conciencia que existe por lo propio, generando aún más el decaimiento de la cabecera municipal, que es deficiente en el tratamiento de las aguas, lo que produce enfermedades en gran cantidad, sin dejar de lado algunas problemáticas sociales que perjudican la tranquilidad en la zona, como el narcotráfico y la intervención de grupos armados al margen de la ley.

De tal manera, la práctica se va enriqueciendo en la medida en que ese proceso de enseñanza-aprendizaje sea mutuo y coherente con los procesos educativos y el desarrollo intelectual que tienen los niños en la Institución Educativa Comercial Litoral Pacífico (Inelpac) en la población de Bocas de Satinga, interviniendo en el desarrollo colectivo de una comunidad y la apropiación de su territorio. 
Al encontrar en los niños del grado cuarto de primaria del (Inelpac) gran asombro por aprender e investigar acerca de su territorio, esto permitió orientar las diferentes actividades y estrategias didácticas con miras a desarrollar mayor capacidad de escucha, autonomía, compañerismo, comprendiendo diferentes formas de ver y de vivir la vida, dependiendo de lo que conocemos, hacemos y reflexionamos, caracterizado en cada una de las respuestas dadas y dibujos que representaban lo que imaginaban y visualizaban de las mismas experiencias adquiridas en su contexto. Además, este proceso generó reflexiones continuas del cuidado y conservación del ambiente que nos pertenece, inculcando conciencia respecto al daño que como seres humanos le hacemos a nuestro país y al mundo entero.

En conclusión, el desafío que se tiene como licenciado en Biología es la importancia de interactuar en un contexto cultural y biológico, para propiciar un dialogo entre el saber local y el saber científico de manera que como futuros licenciados en Biología se valore y promueva el conocimiento tradicional y los recursos biológicos en una perspectiva amplia entorno a la relación del ser humano con la naturaleza, la investigación y la conservación de la diversidad biológica y cultural de nuestro país, consolidándose a partir de intereses académicos y necesidades de la comunidad de manera que este proyecto investigativo de solución de problemáticas locales. Esto fortalece el plan de vida en la institución y comunidad mediante los conocimientos heredados con un alto desarrollo intercultural adecuado y coherente con ética de manejo y conservación del ambiente.

\section{Agradecimientos}

Agradezco en especial a la institución Educativa Comercial Litoral Pacífico (Inelpac) y a su director Alirio Sánchez, ya que con su colaboración y compromiso hicieron de este proyecto investigativo posible. Al profesor Marcial Vallecilla que, como un ejemplo a seguir, permitió guiar este proceso formativo y la participación de los estudiantes del grado cuarto de primaria que con su inocencia reflejaron lo lindo de la niñez y la felicidad.

Gratifico también la confianza, la dedicación y el apoyo brindado por el profesor y asesor de esta práctica integral II, Marco Tulio Peña, por enriquecer este proceso pedagógico y orientar mi formación como licenciada en biología.

$\mathrm{Y}$, por último, pero no menos importante, a Dios y a mis padres, José Antonio Angulo Castillo y Marlen Alive Quiñones Araujo, por ser parte significativa de mi vida, de mis proyectos y por haberme brindado ese apoyo incondicional que desde un principio necesité.

\section{Referencias}

Baéz, J., y Tudela, P. (2009). Investigacion cualitativa. Memoria para optar al grado de doctor. Madrid.

Borja, M. (s.f.). La pedagogía crítica y la contextualización de la enseñanza. Recuperado de https:// guayacan.uninorte.edu.co/divisiones/iese/lumen/ ediciones/4/articulos/monica_borja.html

Buinaje, A. (2013). La maloca uito como espacio educativo de vida desde los principios tradicionales del clan Eimen+ de la etnia uitoto de la chorrera amazonas, Colombia (tesis de grado en Licenciatura en Biología). Universidad Pedagógica Nacional, Bogotá, Colombia.

Castro, C. (2009). Concepciones de los estudiantes de grado octavo sobre el concepto de semejanza (tesis de grado en Magister en Docencia e Investigacion Universitaria). Universidad Sergio Arboleda, Bogotá, Colombia.

Cerda, H. (1993). Los elementos de la investigación: como reconocerlos, diseñarlos y construirlos. Bogotá: El Búho.

Córdoba, D., y Rovira, C. (2004). Descubriendo mi identidad: Catedra Afrocolombiana $4 .^{\circ}$ y $5 .^{\circ}$ grado basica primaria. Bogotá: Corporacion Identidad Cultural.

Ferreiro, E. (2001). Pasado y presente de los verbos leer y escribir. México: Fondo de Cultura Económica.

Francesco, I. (2011). Modelo Pedagógico Holístico Transformador. Fundamentos, dimensiones, programas y proyectos en la Escuela Transformadora. CORIPET: Colombia, pp. 22-207.

Guber, R. (2001). La etnografía, método, campo y reflexividad. Bogota: Norma.

Francesco, I. (2003). La educacion integral en el preescolar: propuesta pedagogica. Bogotá: Magisterio.

Ilipac. (1997-2002). Articulo sobre el Proyecto Educativo Institucional hacia la Calidad Educativa. Municipio Olaya Herrera, Bocas de Satinga.

Martínez, M. (2006). La investigacion cualitativa (sintesís conceptual). Revista IIPSI. Facultad de Psicologia, 9, 123-146. Perú.

Ministerio de Educación Nacional. (1996). La etnoeducación: realidad y esperanza de los pueblos indígenas y afrocolombianos. Bogotá: Ministerio de Educación Nacional.

Ministerio del Ambiente. (2007a). Formulacion del Esquema de Ordenamiento Territorial Municipiod 
de Olaya Herrera. Diagnóstico dimensión sociocultural. Municipio Olaya Herrera: Alcaldia Municipal Olaya Herrera, Universidad de Cauca.

Ministerio del Ambiente. (2007b). Formulacion del Esquema de Ordenamiento Territorial Municipio de Olaya Herrera. Diagnostico de riesgos. Municipio Olaya Herrera, Bocas de Satinga, Departamento de Nariño: Alcaldia Municipal Olaya Herrera - Universidad del Cauca.

Ministerio de Cultura Republica de Colombia. (s.f.). Aqui se puede leer, La corporacion japonea y el Plan Nacional de Lectura y Bibliotecas. Bogotá , Colombia.

Pelaéz, A., Rodiguez, J., \& etal. (s.f.). La entrevista. Universidad Autnóma de Madrid.

Peña, M. T. (2012). La Investigación Educativa en Contextos Bioculturalmente diversos: Notas para reflexionar (manuscrito no publicado). Departamento de Biologia Universidad Pedagogica Nacional, Bogotá, Colombia.

Peña, M. (2013). Taller de análisis interpretativo (manuscrito no publicado). Bogotá, Colombia.

Rocha, M. (2010). El sol babea jugo de piña. Antologia de las literaturas indigenas del Atlantico, el Pacifico y la Serranía del Perijá. Bogotá: Ministerio de Cultura, Biblioteca básica de los pueblos indígenas de Colombia.

Segura, E., Climaco, H. (2004). Factores que han propiciado la inasistencia Escolar (trabajo de grado en Normalista Suerior Etno-Educativo con énfasis en Ciencias Naturales). Institucion Educativa Normal Superior La Inmaculada (INEDIN), Barbacoas, Nariño.Toledo, V., y Barrera, N. (2008). La memoria biocultural. Importancia ecológica de las sabidurias tradicionales. Barcelona: Icaria. 
